\title{
Cervical Cancer cT0 TNM Finding v7
}

National Cancer Institute

\section{Source}

National Cancer Institute. Cervical Cancer cTO TNM Finding v7. NCI Thesaurus. Code C89481.

Cervical cancer with no evidence of primary tumor. (from AJCC 7th Ed.) 